\title{
Alan Williams, Sarah Stewart, Almut Hintze (eds.). The Zoroastrian Flame. Exploring Religion, History and Tradition
}

Samra Azarnouche

\author{
(2) OpenEdition \\ Journals \\ Édition électronique \\ URL : http://journals.openedition.org/abstractairanica/43665 \\ DOI : 10.4000/abstractairanica.43665 \\ ISBN : 1961-960X \\ ISSN : 1961-960X \\ Éditeur : \\ CNRS (UMR 7528 Mondes iraniens et indiens), Éditions de l'IFRI
}

\section{Référence électronique}

Samra Azarnouche, «Alan Williams, Sarah Stewart, Almut Hintze (eds.). The Zoroastrian Flame.

Exploring Religion, History and Tradition », Abstracta Iranica [En ligne], Volume 37-38-39 | 2018, document 8, mis en ligne le 30 décembre 2018, consulté le 28 septembre 2020. URL : http://

journals.openedition.org/abstractairanica/43665; DOI : https://doi.org/10.4000/abstractairanica 43665

Ce document a été généré automatiquement le 28 septembre 2020.

Tous droits réservés 


\title{
Alan Williams, Sarah Stewart, Almut Hintze (eds.). The Zoroastrian Flame. Exploring Religion, History and Tradition
}

\author{
Samra Azarnouche
}

\section{RÉFÉRENCE}

Alan Williams, Sarah Stewart, Almut Hintze (eds.). The Zoroastrian Flame. Exploring Religion, History and Tradition. London-New York: I.B. Tauris, 2016, xviii+382, ill., index.

1 Actes du colloque intitulé «Looking Back: Zoroastrian Identity Formation through Recourse to the Past » qui s'est tenu à la SOAS en 2013 à l'occasion de l'inauguration de l'exposition "The Everlasting Flame: Zoroastrianism in History and Imagination », rassemblant 18 contributions réparties en quatre grandes sections: 1 . Thèmes et approches: Répondant à des exigences aussi existentielles que théologiques, les procédés de rétrospection du zoroastrisme se rapportent, selon Ph. G. Kreyenbroek, à la figure prophétique de Zarathushtra et à sa place dans les Gāthā (p. 13-25). «Comment les études zoroastriennes sont façonnées par la subjectivité/objectivité de ses chercheurs? ", s'interroge Y. S. Vevaina dans une intervention originale sur la sociologie du savoir, en livrant des anecdotes sur ses propres expériences de « critical insider » (p. 27-57).

2 2. Antiquité et tradition: La structure de la cérémonie du Yasna, ainsi que le matériel épigraphique, permettent de faire remonter ce sacrifice à l'époque achéménide, comme le démontre A. Cantera (p. 61-76). Il permettrait l'accès à la «Vision», ou daēnā, qu'A. Hintze retrace dans sa contribution à travers les sources iconographiques centrasiatiques, où cette divinité jouissait d'un statut à part (p. 77-96). L'articulation parfois sensible - entre la tradition textuelle et la pratique rituelle est analysée par le 
Dastur F. Kotwal à l'appui d'exemples de divergence et des transformations entre les panthak (p. 97-111). Les liens entre l'astrologie et la cosmologie sont éclairés par A. Panaino en se référant à la doctrine millénariste et le cycle des 12000 ans (p. 113-133). T. Daryaee revient sur la question du modèle historiographique à la période sassanide tardive basé sur la mythologie des Yašt, tout en rappelant le problème de la rareté des sources avant le $5^{\mathrm{e}}$ siècle (p. 135-144).

3 3. Tradition et culture : J. Russell livre une étude sur la figure de Zarathushtra, entre textes et images, notamment arméniens (p. 147-178). L'art achéménide et sassanide, en particulier les bas-reliefs royaux, semblent avoir été, comme le montre V. Curtis, la principale source d'image pour les zoroastriens (p. 179-203). F. Grenet interprète le plat Soltikoff de la BNF comme une représentation des principales fêtes zoroastrienne (p. 205-221). A. de Jong tente de montrer le rôle actif des zoroastriens à Bagdad à l'époque califale, seul creuset intellectuel où le compendium du Dēnkard aurait pu voir le jour (p. 223-238). La notion d'amitié (dōstîh) et son rapport aux autres vertus zoroastriennes sont discutés par J. Choksy à travers les sources moyen-perses (mais sans établir de lien avec son parallèle néoplatonicien) (p. 239-248). En examinant les vers de Daqiqi empruntés par Ferdowsi, A. Dahlén montre l'adéquation du discours du poète, cristallisé autour de la figure d'Esfandiyār, avec la pensée zoroastrienne (p. 249-276).

4 4. Modernité et minorités : L'étude de la symbolique des vêtements rituels (sudra et kusti) à l'époque contemporaine et de leur mode de tissage est le projet que mène Sh. Cama (p. 279-294). La contribution des Parsis aux activités économiques des Indes et plus tard à la culture matérielle et intellectuelle des États Unis est définie par J. Rose (p. 295-320). Toujours dans nos sociétés modernes, R. Foltz identifie des courants kurdes et tajiks qui revendiquent l'héritage de Zoroastre pour se différencier de l'islam (p. 321-337). Kh. Mistree présente des cas historiques où les Parsis ont dû entrer en conflit avec des non-zoroastriens pour préserver leur identité et leurs institutions (p. 339-352). Enfin, S. Stewart s'interroge sur l'autodéfinition des zoroastriens d'Iran, par rapport au reste des Iraniens et par rapport aux zoroastriens vivant hors de l'Iran (p. 353-370).

\section{AUTEURS}

\section{SAMRA AZARNOUCHE}

EPHE, Mondes iranien et indien, Paris 